FACTA UNIVERSITATIS

Series: Working and Living Environmental Protection Vol. 14, No 3, 2017, pp. 197 - 206

https://doi.org/10.22190/FUWLEP1703197J

\title{
ON A METAL FIRE DETECTION
}

UDC 614.841-034

\author{
Nada Jovičić \\ Technical school, Užice, Serbia
}

\begin{abstract}
The aim of this paper is to analyze possibilities of metal fire detection using various types of fire detectors, and find the most convenient type of detector. Metal fires belong to class $D$ fires, and demand extinguishing agents which work by smothering and heat absorption. On the other hand, it is too risky to use heat generated by fire for early-stage detection due to high heat release rate. Some metals burn with smoke, but during the fire, most of them produce significant ultraviolet and infrared component of radiation which can be used for detection. Therefore, this paper analyzes the possibility of using a flame detector in case of metal fires, as well as sitting and spacing of flame detectors for metal fire detection at its earliest stage.
\end{abstract}

Key words: metal fires, detection, flame detectors

\section{INTRODUCTION}

Combustible metal fires, reactions between non-metals and other compounds, such as crushed magnesium fires $(\mathrm{Mg})$, aluminum $(\mathrm{Al})$, sodium reactions $(\mathrm{Na})$, potassium $(\mathrm{K})$, lithium ( $\mathrm{Li}$ ) and others, belong to class $\mathrm{D}$ fires. This class is not common in everyday life and work activities, but it is characteristic for laboratories and industrial plants. Due to the specific nature of these materials, the use of water as means of putting the fire out is strictly forbidden. The reason for this is high temperatures and thermal decomposition of water, and the release of hydrogen $\left(\mathrm{H}_{2}\right)$ which is known to be explosive. For putting out such fires, special powders on a sodium-chloride $(\mathrm{NaCl})$ or other salt basis are used. Class D fires can also be put out with dry sand.

Combustible metals are widely used in today's modern industries, from the manufacturing of batteries all the way to the aviation industry, among them most notably aluminum ( $\mathrm{Al}$ ), magnesium $(\mathrm{Mg})$, titanium $(\mathrm{Ti})$, lithium, and their alloys. When used in manufacturing they can come in a variety of shapes and sizes, from levers and bars, to smaller pieces and powder, while the final products can be tiny pieces but also intricate air-plane parts.

Received October 28, 2017 / Accepted January 7, 2018

Corresponding author: Nada Jovičić

Technical school, Sveti Sava Square 34, 31000 Užice, Serbia

E-mail: 974nada@gmail.com 
The greatest risks of a fire hazard occur during the processing of these metals using dry grinding techniques, but also grinding and polishing. Ignition and explosions can occur in the following situations: during the adaptation of combustible metals in melting and casting; by chemical reactions of metals in liquid form with other substances; in cases when this type of materials is in the form similar to wood chips, or when there are other adequate conditions for a fire breaking out. The dust from these metals is highly flammable and explosive, with each explosion being of a larger scale.

The largest number of combustible metals belongs to the colored light metals whose typical representatives are magnesium $(\mathrm{Mg})$ and aluminum $(\mathrm{Al})$. These metals have the largest usage in the making of auto parts (wheels, chassis), electric devices, in airplane and construction industries, and electronic industry. Thanks to its light weight and good mechanic and electric properties, magnesium $(\mathrm{Mg})$ is used in the making of mobile phones, phones, laptops and tablet computers, cameras and other electronic components, but also in making artificial light in photography, and in the airplane industry and astronautics. In the form of powder, magnesium $(\mathrm{Mg})$ is used as fuel in reactors. As a deoxidant, it is used in steel metallurgy of coloured metals.

Due to the above listed facts, it is obvious that special care and attention are needed when designing a system which is supposed to detect a class D fire. Being that the most important part in the planning is the choice of the adequate type of a detector, one must, before engaging in the design of the very detector, posses a knowledge of the basic attributes and characteristic of the materials which cause a class D fire, above all, the characteristics of burning and the products of combustion which accompany the fire.

\section{BASIC CHARACTERISTICS OF FLAMMABLE METALS}

It is known that the combustion of firm fuel materials has two phases: a gas burning phase and a solid burning phase. The temperature of the solid burning phase depends on the size of the particles; that being said, the smaller the solid fuel material is, the bigger the surface of the material that comes into contact with air is. It directly raises the possibility for oxidation - the temperature of ignition is lower, whereas the chance of self combustion is larger. This is a very important attribute for making the conditions for the ignition of the metals.

Self combustion is possible without the presence of an external source, due to self heating which occurs as a result of chemical, physical and biological processes. The period from the beginning of the heating until the occurrence of flames is shorter for gases and liquids, while it is longer with solids. If the solids are present in the form of dust, the time is considerably shorter. Inflation temperature is influenced by the percentage of humidity, the form of the flammable substance and the content of the substance, which cannot be determined as a precise temperature point. The increase in pressure decreases the self-ignition temperature due to smaller distance between the particles of the mixture. This is due to the increasing number of collisions which speed up the reaction within the mixture. Substances that are prone to self-combustion and self-heating along lignite, wood shavings, liquid fuels, fats and oils are also fine metal powders. This group includes alkaline and alkaline earth metals, and some other metals, if they are in the form of dust, such as iron (Fe), cobalt (Co), nickel $(\mathrm{Ni})$, titanium $(\mathrm{Ti})$, copper $(\mathrm{Cu})$, aluminum $(\mathrm{Al})$, magnesium $(\mathrm{Mg})$, etc. 
The mechanism of the formation of fire of combustible metals depends on several factors, and above all on the reactions with water and other compounds. For example, an exothermic reaction of sodium $(\mathrm{Na})$ with water can cause the release of separated hydrogen $\left(\mathrm{H}_{2}\right)$, causing a fire or explosion hazard. Sodium $(\mathrm{Na})$ can also indulge itself in the air if the granulation of chopped grains is low enough. Similar to sodium is also potassium $(\mathrm{K})$, which, unlike sodium, can explode in contact with liquid bromine $(\mathrm{Br})$. Reactivity decreases as you go down the group. For example, lithium (Li) can be ignored only at a temperature above $180^{\circ} \mathrm{C}$, but it can explode after treatment with nitric acid $\left(\mathrm{HNO}_{3}\right)$ only on a slight stroke or friction.

Magnesium (Mg) is a highly flammable metal, regardless of the form, and its ignition temperature is close to the melting point at $650{ }^{\circ} \mathrm{C}$, or much lower depending on the shape in which it is located. In the form of a cloud of dust, magnesium $(\mathrm{Mg}$ ) burns extremely quickly, even its chips are easy to burn, especially when it is soiled with oil and then prone to self-ignition. Magnesium dust produces an explosive atmosphere with air and can sparkle.

Hafnium (Hf), Plutonium (Pu), Thorium (Th), Uranium (U) and Zirconium ( $\mathrm{Zr}$ ) are classified as highly flammable metals with similar fire and explosion hazards as magnesium.

\section{Characteristic of Flammable Metal Fires from the Aspect Of Detection}

It is usually said that a fire alarm system must detect the fire at the earliest stage. When it comes to class D fires, which include metal fires, the detection time is crucial because of the time frames within which the extinguishing system needs to be activated.

The burning characteristics of most flammable metals are similar to the burning characteristics of most Class A materials, such as wood or paper. Similar to materials belonging to class $\mathrm{A}$, the amount of energy required to trigger metal ignition depends on the fuel configuration - much more energy is required to ignite larger pieces of metal than dust or shavings resulting from processing. Some metals melt, while others remain in solid state during burning. The development and increase in flame intensity during burning is most often measured in minutes and is similar to flame that occurs in the fire of materials belonging to class A rather than class B.

When the burning process begins, most flammable metals react violently in contact with water, while some metals (sodium, lithium) react with water even when not ignited. Some metals give a smallest or greater amount of smoke during burning - titanium gives very little smoke during combustion, while the lithium fire is accompanied by a large amount of dense smoke. Sodium melts and flows as it burns, while calcium does not. Some metals, such as uranium, are easier to ignite during longer exposure in areas with high moisture content, but if they are in an ambient with dry air it makes it difficult to ignite. Magnesium burns with a very light flame, whereas the flame radiation spectrum during its combustion contains a significant part of ultraviolet radiation.

Because of the above-mentioned reasons, when it comes to planning and design of fire detection system for compartments in which fires of combustible metals can appear, it is inevitable to be familiar with the characteristics of the combustion from the start. 


\section{THE SUITABILITY OF CERTAIN TYPES OF DETECTORS FOR FLAMMABLE METALS FIRE DETECTION}

Generally speaking, the detection of flammable metal fires, and in general detection of class D fires, is a far greater problem when it comes to fire detection in other classes. The reasons for this conclusion lie in the fact that, depending on the type of combustible material, the combustion products include heat, smoke or flame, and on the other hand the response of the detector must be very fast because this type of fire develops faster than fires of material which belong to other classes of fire.

Heat detectors. Most metals emit a very large amount of heat during the burning process, with far greater temperatures than those that occur during the burning of materials belonging to class $\mathrm{A}$ or class $\mathrm{B}$. As the heat produced during fire is limited by the fire surface, it is known that heat detectors are the most inertial to the rest, this is due to a potential delay in the very detection, which can lead to a late response. Because of these facts, heat detectors (dotted or linear) could be an acceptable solution only if they are located near the flammable metal. In other words, the coverage area and the mutual distance between the detectors should be significantly less than the one prescribed by the standard (SRPS) EN 54-14, which leads to a redundant and significantly more expensive system.

If we use point type detectors that are placed on the ceiling of the space to be protected, the question arises as to whether fire is detected before it hits the entire room. Line type heat detectors are more acceptable due to the fact that the cable (thermosetting, viscous, optical, etc.) does not have to be placed on the ceiling, but it can be placed on the floor, or be "drained" through a part of the room with a risky content, whereby the distance between the individual segments of the detector line can be reduced according to the content of the object.

Smoke detectors. Smoke detectors today are the most common type of fire detectors and occupy more than $90 \%$ of installed detectors in the world, referring mostly and primarily to housing facilities. Their application in the detection of inflammable metals and, in various types of technological processes is limited by the fact that, regardless of having the ability to auto calibrate, they are not suitable for work in "dirty" environments. Namely, in environments where a larger amount of dust is generated, and especially where operations such as scraping, grinding and the like are performed, the dotted smoke detector is quickly becoming unreliable due to precipitated dust in the chamber. This problem in certain technological processes can be solved by a dust extraction system (for example, wood industry), but in technological processes where flammable metals are used, this is not the case.

Line type smoke detectors are a better solution due to the auto compensation of slow changes in percentage of the darkening of the room, but here again the basic problem is whether flammable metal produces enough smoke that will "cut" the infrared air from the transmitter and generate an alarm signal.

Flame detectors. Flame detectors generally give the fastest response, but for them it is necessary to "see" the fire in the direct line, i.e. that there are no obstacles between the detectors and the potential location of the outbreak. Since these detectors (ultraviolet, infrared, and a combination of these ranges) are primarily intended for the detection of hydrocarbon fires, it is necessary to choose a type of detector that is sensitive to the extent of flame radiation of the metal, in cases when fire is expected.

In the following text, we analyzed the suitability of the flame detector for detecting the fire of metals, precisely because of the fact that flame detectors can react to different flashes of wavelengths in the market today. 


\section{DeteCtion OF METAL Fire by Flame DETECTORS}

Based on the previously presented facts, it is suggested that flame detectors are most suitable for detection of fire of flammable metals. However, in order to arrive at a correct conclusion on the type of appropriate flame detector and the method of its application, it is necessary to provide other facts related to the scope of detection.

Flame detectors are particularly suitable for the detection of hydrocarbon fires. Although the flame radiation spectrum has a different composition by intensity and diapason, and depends on the composition of the fuel matter, the temperature and the combustion rate, it is possible to define a specific form of radiation spectrum for the specific fuel. The typical appearance of the spectrum that occurs in the fire of petroleum products is shown in Figure 1.

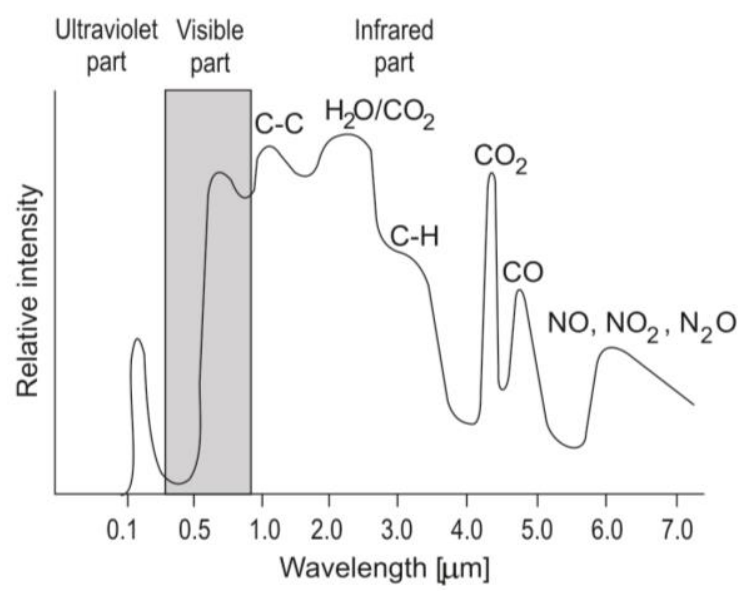

Fig. 1 Spectrum of the flame of gasoline fire

Therefore, if - the spectrum of the flame radiation of a flammable metal is known, it is possible to choose the appropriate flame detector.

The types of flame detectors classified by wavelength which are used for detection, as well as the technology applied are as follows:

- ultraviolet (UV) - wavelength up to $0.38 \mu \mathrm{m}$,

- approximately infrared - in the range of $0.78 \mu \mathrm{m}$ to $1.3 \mu \mathrm{m}$

- infrared (IR) - in the range of $1.3 \mu \mathrm{m}$ to $10 \mu \mathrm{m}$

- combined - they represent the combination of the two previous types: UV / IR, IR2 (two IC sensors), IR3 (three IC sensors) and multi IR (contain multiple IC sensors).

The previous classification is more theoretical, because UV and IR flame detectors are used in practice, with a slightly different scope of detection defined by the European standard. ${ }^{2}$

\footnotetext{
${ }^{2}$ Definitions from the international standard ISO 7240-10 and the European standard EN 54-10: Point flame detectors

3.1 infrared (IR) detector - flame detector responding only to radiation having wavelengths greater then $850 \mathrm{~nm}$. 3.2 ultra-violet (UV) detector - flame detector responding only to radiation having wavelengths less then $300 \mathrm{~nm}$. 3.3 multiband detector - a flame detector having two or more sensing elements, each responding to radiation in a distinct wavelength range and each of whose outputs may contribute to the alarm decision.
} 
A typical spectrum of hydrocarbon flame radiation with a wavelength range that uses standard types of ultraviolet and infrared flame detector is shown in Figure 2.

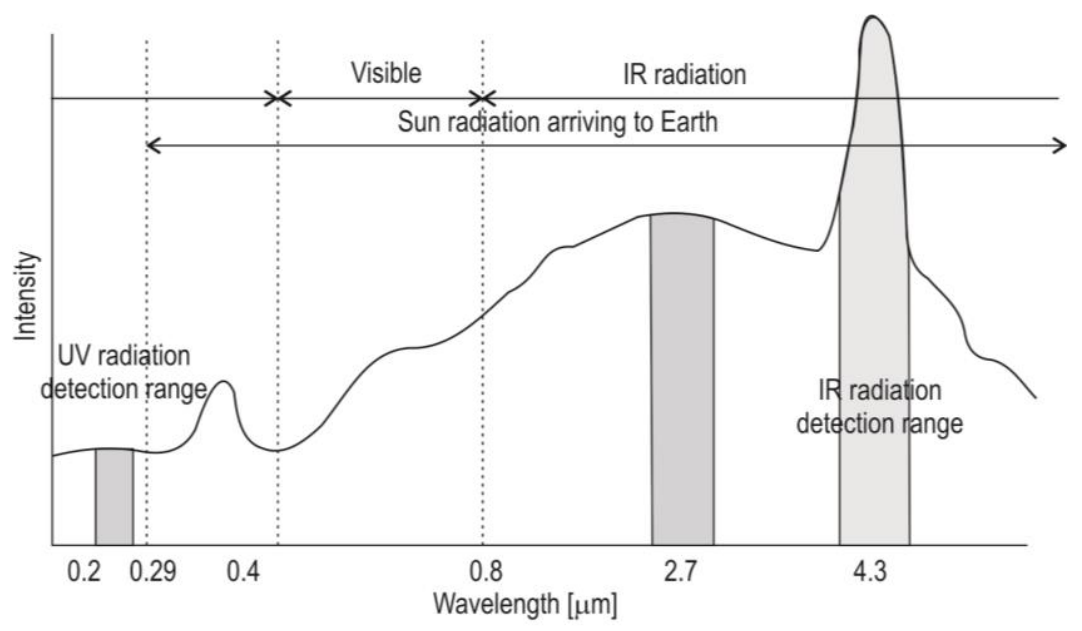

Fig. 2 A "typical" spectrum of hydrocarbon fires

As seen from the previous figure, ultraviolet flame detection detectors use a narrow frequency range of UV radiation and an UV-C component with a wavelength in the range of $280 \mathrm{~nm}$ to $100 \mathrm{~nm}$. As the energy of UV radiation that comes to the surface of the Earth is composed mainly of UV-A and a small part of the UV-B component, for the detection of the fire, the UV-C component in which the ionization comes in has the greatest energy. The generally accepted ionization limit is at wavelengths ranging from $100 \mathrm{~nm}$ and photon energy greater than $12.4 \mathrm{eV}$.

On the other hand, standard types of infrared flame detectors react to the infrared portion of the spectrum that is characteristic of the open fire and to the frequency corresponding to flicker of the flame. Infrared flame detectors use an area of the spectrum between $4.15 \mu \mathrm{m}$ and $4.55 \mu \mathrm{m}$ and additionally evaluate the flashing of the flame of a frequency of 5 to $30 \mathrm{~Hz}$. However, the wavelength of the parts in the IC range of the flammable metals is moving lower, in the part from $2.5 \mu \mathrm{m}$ to $3.0 \mu \mathrm{m}$.

On the basis of the exposed, ultraviolet flame detectors are installed as an optimum choice for detection of fire of inflammable metals. The reasons for this are the following:

- Most of the flammable metal fires give an intense ultraviolet component in the part of the range that is detected by most of the ultraviolet flame detectors present on the market today,

- The ultraviolet flame detector's response is of the order of less than $10 \mathrm{~ms}$, which is convincingly the fastest response to all other types of fire detectors,

- They are practically insensitive to the radiation of the Sun (and therefore the sunlight cannot lead to false alarms) since the UV-C component of the solar radiation, which is used for detection, is absorbed by the ozone layer.

However, ultraviolet flame detectors have one major defect that determines their usage - UV radiation is easily absorbed due to the occurrence of dust or impurities on the detector. Moreover, even in conditions when the detector is kept completely clean, if the 
fire is accompanied by small amounts of smoke, smoke acts as an absorbent that will affect the amount of UV radiation that comes to the detector.

Having these facts in mind, the solution is a flame detector which, in addition to detecting in the UV part of the spectrum, performs detection and IC components and combines signals most often with the "I" logic circuit to generate an alarm signal. The combination with IC component of the flame detector is important here because, although in general the IC detector is insensitive to the flame of a flammable metal, this type of detector takes into account the flame flicker frequency when generating the alarms, which is not the case with the UV detectors.

In other words, the most suitable combination of sensors within the flame detector for detection of flammable metals would be a combination of UV and IC detectors, where the IC component should be sensitive to IC radiation in the range of $2.5 \mu \mathrm{m}$ to $3.0 \mu \mathrm{m}$. Table 1 lists the sensitivity of individual types of flame detectors.

Table 1 Sensitivity of individual types of flame detector to metal fire

\begin{tabular}{lccccc}
\hline Detector type & UV & IR & UV/IR & IR3 & Multi IR \\
\hline Grade & 2 & 4 & 3 & 4 & 4 \\
\hline
\end{tabular}

Grades: $1-100 \%$ to $75 \%$ sensitivity, $2-75 \%$ to $50 \%$ sensitivity, $3-50 \%$ to $25 \%$ sensitivity, 4 - Not applicable

\section{Metal FiRES Detection by Flame Detectors}

Siting and spacing a flame detector, although based on the rules defined in EN 54-14 Fire detection and alarm systems - Planning, design, installation, commissioning, use and maintenance, in areas where fire of flammable metals is expected to be subject to certain codifications, in some cases may represent a significant redundancy. Namely, it is known that electromagnetic radiation (i.e., flame radiation) decreases with the square of the distance, which means that only $1 / 4$ of the energy of the flame radiation arrives by doubling the distance of the detector from the fire to the detector. In other words, if the flame detector had the same response time, and if the detector distance is increased twice from the possible place of fire, the flame surface must be four times higher (see Figure 3). ${ }^{3}$

This fact is vital, because one must remember when placing fire detecting devices, in the initial phase of ignition that the area of the combustible metal is usually very small. Furthermore, the calculation of effective control can be facilitated by the fact that some manufacturers define the sensitivity of the flame detector indirectly, over a percentage of the distance from the source of radiation. The standard sensitivity is $2 \%$, which in practice means

\footnotetext{
${ }^{3}$ To test the range of flame detectors in accordance with EN 54-10, two types of "flame test" are used: a yellow flame of $0.1 \mathrm{~m}^{2}(33 \times 33 \mathrm{~cm})$ and an invisible flame (flame of alcohol) of $0.25 \mathrm{~m}^{2}(50 \times 50 \mathrm{~cm})$.

${ }^{3}$ EN 54 Fire detection and fire alarm systems Part 10: Flame detectors - Point detectors, 5.5.3 Classification The detector shall be classified according to the greatest distance at which all eight specimens respond to each fire type within the $30 \mathrm{~s}$ exposure. The classes shall be:

Class 1 if all specimens respond to both fire types at distances up to and including $25 \mathrm{~m}$

Class 2 if all specimens respond to both fire types at distances up to and including $17 \mathrm{~m}$

Class 3 if all specimens respond to both fire types at distances of $12 \mathrm{~m}$

If any spacimen fails to respond to one or both fire types at a distance of $12 \mathrm{~m}$, it shall not be classified.
} 
that the detector can detect a flame that is $2 \%$ high in relation to the distance from the caller. In other words, Class 1 (Range $25 \mathrm{~m}$ ) will detect a flame that is at least $50 \mathrm{~cm}$ high.
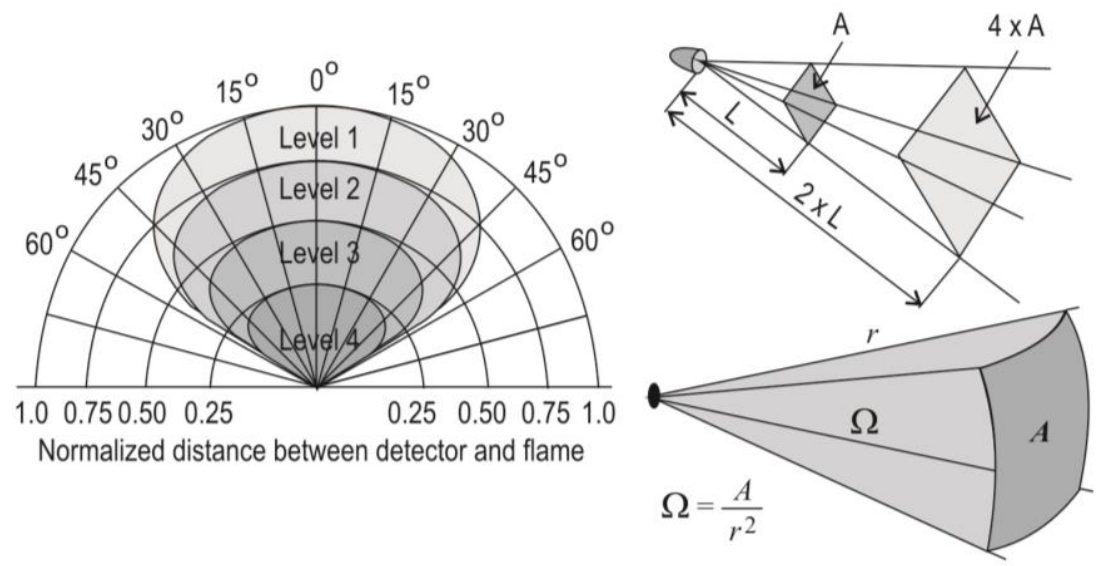

Fig. 3 Field of "view" and decreasing with the "square of the distance"

Therefore, the angle of coverage, or the field of "view" of the detector in the case of metal fire detection should be reduced to a maximum of 50 to $60^{\circ}$ of the spatial angle with a reduction in the maximum distance from the point of fire to a maximum of $50 \%$ of the normalized distance. In accordance with these and the estimations given in Table 1, Figure 4 shows the horizontal and vertical field of "view" of the flame detectors recommended for detection of a metal fire.

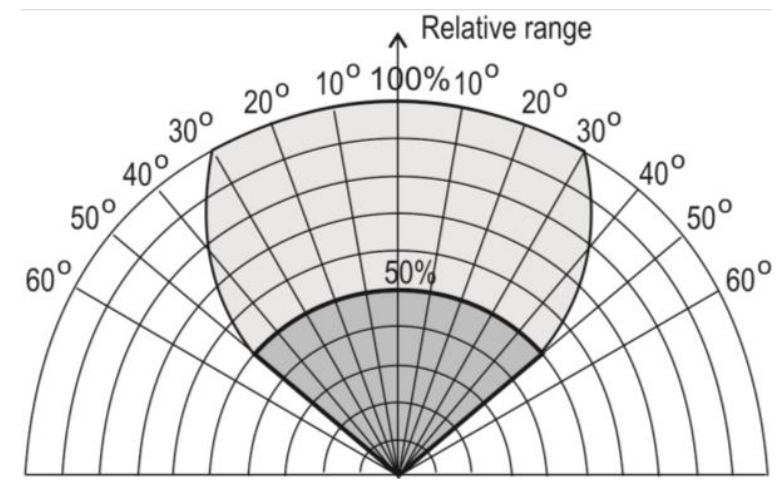

Fig. 4 The horizontal and vertical "field of view" of a fire detector for combustible metal fires

The reduction of the field of coverage, of a fire detector, to just $50^{\circ}$ spatial degrees and to a $50 \%$ of the maximum declared distance for detection, in accordance to the EN 54-10 standard, needs more fire detectors to be installed when a fire caused by combustible metals is expected. The simplest action of precaution is to use multiple fire detectors as to achieve the coverage of a full circle angle of degree. That is, to achieve such coverage $\left(360^{\circ}\right)$, with a limitary space angle of $60^{\circ}$, six fire detectors need to be 
used, all positioned on the rim of the virtual circle around that area. Thereby doing so, one must, of course keep in mind the basics rules about the placement of fire detectors such as - fire detectors are to be placed in pairs, facing each other. An example of fire detector placement in a room with non-standards geometric layout is shown in Figure 5.
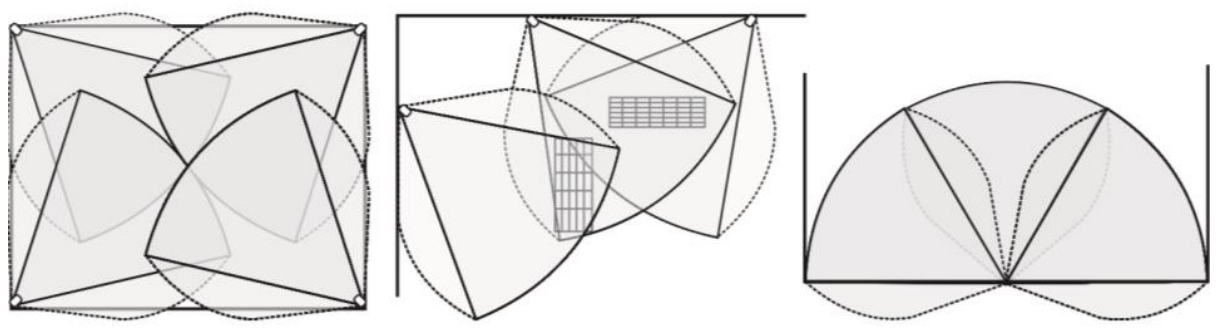

Fig. 5 An example of flame detector placement for detecting combustible metal fires

Obviously, in the case of flame detectors usage for metal fire detection, there is a necessity of redundancy, which makes the system more expensive, but increases reliability of fire detection system.

\section{CONCLUSION}

In case of metal fires, the flame detectors take advantage of reliable detection in regard to other types of fire detectors. But, because "square of the distance" is low, the field of "view" and spacing between flame detectors must be reduced, which leads to redundancy in fire detection system design and consequently, to higher price of the system. However, decreasing the distance between flame detectors affect reliability and response time of the whole system, and therefore, the moment of the beginning of extinguishing, This approach is absolutely valid, keeping in mind the types of combustion products of metal fires.

\section{REFERENCES}

1. Blagojević M., Alarmni sistemi, monografija, 2. ispravljeno i dopunjeno izdanje, Fakultet zaštite na radu u Nišu, ISBN 978-86-6093-070-7, 2015.

2. Blagojevic M., Petkovic D., Detecting fire in early stage - a new approach, Facta Universitatis - Series: Working and Living Environment Protection, Vol 2, No 1, 2001, ISSN 0354-84.

3. DET-TRONICS: Optical Flame Detection Solutions, http://www.dettronics.com/ProductCatalog/FlameDetection/Documents/92-1068-2.1-Flame-Brochure.pdf

4. DOE HANDBOOK: Primer on spontaneous heating and pyrophoricity, U.S. Department of energy, Washington, D.C. 20585, 1994.

5. EN 54-14: Fire detection and fire alarm systems, Guidelines for planning, design, installation, commissioning, use and maintenance, 2004.

6. EN 54-10: Fire detection and fire alarm systems, Flame detectors - Point detectors, 2006. 


\section{O DETEKCIJI POŽARA METALA}

U radu su analizirane mogućnosti pojedinih tipova detektora požara za otkrivanje požara metala, predložen najpogodniji tip detektora. Požari metala spadaju u klasu požara $D$ i zahtevaju posebna sredstva gašenje koja rade na principu prigušivanja i apsorpcije toplote. Na drugoj strani, veoma je rizično da se za detekciju požara u ranoj fazi koristi toplotna snaga požara zbog velike brzine oslobađanja toplote. Neki metali gore sa dimom, ali većina tokom požara oslobađa ultraljubičastu i infracrvenu komponentu zračenja plamena koje mogu biti iskorišćene za detekciju. Zbog toga, u radu je analizirana mogućnost detekcije požara metala korišćenjem detektora plamena, kao i način postavljanja za detekciju požara metala u najranijoj fazi.

Ključne reči: požari metala, detekcija, detektori plamena 